\title{
Promoting Academic Achievement through Positive Relationships
}

\author{
Petraq Buka, Prof Assoc. \\ Tirana University, Faculty of Foreign Languages \\ Tirana, Albania
}

\section{Doi:10.5901/jesr.2013.v4n3p323}

\begin{abstract}
Positive relationships encourage students' motivation and engagement in learning. A powerful weapon available to teachers who want to foster a favourable learning climate is a positive relationship with their students. Improving students' relationships with teachers has important, positive and long-lasting implications for students' academic and social development. Teachers who foster positive relationships with their students create more favourable classroom environments for learning and meet students' emotional and academic needs. Positive teacher-student relationships, that is low conflict and a high degree of closeness and support, contribute to their social skills and promote academic performance. Students who experience positive relationships with their teachers are less likely to avoid school, appeared more more cooperative, and more engaged in learning. Students display better academic performance and experience less loneliness if they have a positive relationship with their teachers. Teachers who show sensitivity to individual differences among students, include students in the decisionmaking and acknowledge students' needs produce greater motivation in their students than those who use fewer such practices. Positive teacher-student relationships can promote improved peer relationships in classrooms through direct and indirect approaches and enhance students' engagement as well as improve student-to-student acceptance.
\end{abstract}

Keywords: Relationship, conflictual, performance, achievement, empathy

Positive relationships encourage students' motivation and engagement in learning. A powerful weapon available to teachers who want to foster a favourable learning climate is a positive relationship with their students. When students feel that you value and care for them as individuals, they are more willing to comply with your wishes. Developing positive teacher-student relations is one of the most effective steps we can take to establish a positive discipline climate in the classroom. When we treat students with respect, they tend to appreciate and like us. When they appreciate and like us, they are more willing to want to please us-which causes them to be more likely to behave appropriately. This is why it is so important to remember that, when it comes to student behaviour, it's more often the relationship students have with us than it is the rules themselves that encourages students to follow those rules.

Improving students' relationships with teachers has important, positive and long-lasting implications for students' academic and social development. Solely improving students' relationships with their teachers will not produce gains in achievement. However, those students who have close, positive relationships with their teachers will attain higher levels of achievement than those students with more conflictual relationships. If a student feels a personal connection to a teacher, has frequent communication with a teacher, and receives more praise than criticism from the teacher, then the student is likely to become more trustful of that teacher, show more engagement in the academic process, display better classroom behavior, and achieve much better academically. Positive teacher-student relationships draw students into the process of learning and promote their desire to learn.

Teachers who foster positive relationships with their students create more favourable classroom environments for learning and meet students' emotional and academic needs. Positive teacher-student relationships, that is low conflict and a high degree of closeness and support, contribute to their social skills and promote academic performance. Students who experience positive relationships with their teachers are less likely to avoid school, appeared more more cooperative, and more engaged in learning. Students display better academic performance and experience less loneliness if they have a positive relationship with their teachers. Teachers who show sensitivity to individual differences among students, include students in the decision-making and acknowledge students' needs produce greater motivation in their students than those who use fewer such practices.

Positive relationships can also help a student develop socially. The presence of positive relationships with teachers and the experience of a positive school environment are strong indicators of academic achievement, much stronger than class size, teacher experience, or availability of instructional means. Students will be more engaged and motivated if teachers meet students' need for social connection. Teacher-student relationships are determined by more 
than one factor: teacher and student characteristics play an important role in predicting the quality of relationship that teachers have with individual students. Other factors such as school social climate, etc. also contribute to the quality of these relationships.

Positive teacher-student relationships appear to complement the other important relationships in students' lives, family relationships, which for younger students, are more important than teacher-student relationships. Middle school students, experience a higher interest in learning and a better engagement in the classroom. At this level, parental support plays a complementary role by fostering youths' motivation in school. Parent and teacher collaboration, combined with parent and teacher monitoring, play a critical role in predicting gains in academic achievement.

Positive teacher-student relationships can promote improved peer relationships in classrooms through direct and indirect approaches. Teachers can directly promote positive social behaviours by orchestrating the relationships within a classroom in a positive manner. Teachers can use positive teacher-student relationships indirectly to promote peer relationships as well. Positive teacher-student relationships enhance students' engagement as well as improve studentto-student acceptance.

Teachers need to make extra efforts to offer the social and emotional support to students who have poor relationships with them, to help them meet the challenges they face in school. Teachers vary in their ability to create positive teacher-student relationships. Some teachers find it easier to develop positive relationships with students. Some personal characteristics of teachers have been identified as important predictors of positive teacher-student relationships. Teachers are more likely to develop close relationships with students who share their same ethnic background. Teachers who recall their own upbringing are also more likely to experience closeness with the students. Teachers who use fewer didactic and more age-appropriate, student-centered teaching practices report less conflictual relationships with their students.

The quality of early teacher-student relationships has a long-lasting impact. Specifically, students who had conflict with their teachers had lower academic achievement and more behavioural problems. Students with more closeness and less conflict with teachers developed better social skills than those with more conflictual relationships. It is easier to focus attention on positive teacher-student relationships in schools where trust and positive relationships are important for improving children's performance. Positive teacher-student relationships play an equally important role in students' success across all subjects. Students' social and emotional needs are present throughout the year, regardless of the subject being taught.

What do positive student-teacher relationships look like in the classroom? Teachers show their pleasure and enjoyment of students. They interact in a responsive and respectful manner and offer students help in achieving academic and social objectives. Teachers demonstrate knowledge about individual students' backgrounds, interests and academic levels and they seldom show irritability toward students.

Positive teacher-student relationships are, however, only one part of a teachers' classroom management and discipline strategies. Positive relationships only complement other aspects of classroom management. Furthermore, it is not possible to develop positive relationships with every student. As teachers, we can strive toward accomplishing that goal but having an ideal relationship with each student may be unobtainable.

Some student characteristics are, however, risk factors for positive relationships. Boys typically have more conflict and less closeness in their relationships with teachers than girls. Students with problematic relationships with family members tend to have poorer quality relationships with their teachers. Students who exhibit more problem behaviors at home and school tend to develop more conflictual and less close relationships with their teachers. Students with poor academic performance are perceived by their teachers as having more conflictual relationships than students with better academic performance.

Positive teacher-student relationships can offset some of the normal problems that students experience as they grow and develop. For example, the transition to middle school is often viewed as a stressful time for children; middle school students often show decline in motivation, self-esteem and academic performance. However, students who perceive greater support from their teachers experience less depression and more self-esteem. Also, students who perceive their teachers as respectful, offering constructive feedback are more motivated in school.

Teachers face numerous demands and challenges in their classrooms. They are expected to meet the needs of diverse learners, and use a variety of strategies that will boost student achievement while they simultaneously develop positive relationships with students who are experiencing personal, social, and cognitive challenges of adolescence. Teaching is complex and cannot be reduced to discrete tasks that can be mastered one at a time. Teachers must "win their students' hearts while getting inside their students' heads". As Haberman suggested, this winning of the hearts occurs through very personal interactions. This perspective is supported by research suggesting that teachers who 
develop such relationships experience fewer classroom behaviour problems and better academic performance.

Classroom management is particularly important in the middle school years when students are more likely to experience decline in academic motivation and self-esteem. The decline can be attributed particularly to teacher-student relationships. Students' interest and motivation for academic achievement decline significantly during adolescence.

One factor to effective classroom management is the development of a quality relationship between the teacher and the students in the classroom. Teachers who have high-quality relationships with students have fewer discipline problems, rule violations, and other related problems than do teachers who do not have such relationships.

An important component of developing relationships is knowing and understanding the learner. Teachers must take steps to learn and understand the qualities of middle school students, who are at a crucial time in their development. Although students are good at disguising their feelings, they are keen to have positive social interaction with peers and adults.

Teachers who adopt a relationship-building approach are more likely to help students develop positive, sociallyappropriate behaviours. Effective teacher-student relationships are not related to the teacher's personality or whether the teacher is respected by the students. Instead, the relationships are characterized by specific behaviours, strategies, and attitudes demonstrated by the teacher. This approach involves taking personal interest in students, establishing clear learning goals and fostering assertive and positive behaviours.

How can teachers engage students through personal interactions while simultaneously managing classroom instruction? The purpose of this article is to suggest specific strategies that integrate knowledge and skills to help teachers develop a strong management system based on the development of personal relationships with students. These techniques are specifically adapted for use by teachers for the purpose of making education more effective. Teachers do not treat all students equally, they employ different strategies with different types of students. Teachers with effective classroom management skills are aware of the needs of students and use specific techniques to meet their needs.

According to Wolk, "Teacher-student relationships might help or hinder learning and affect everything from curriculum to choice of teaching methods." Building relationships as a means to manage classrooms includes recommendations such as using gentle interventions, avoiding punishments, and building activities that ensure success for all students. These strategies, though helpful, may still leave teachers struggling with the most difficult students. Rogers and Renard asserted that "we need to understand the needs and beliefs of our students as they are, not as we think they ought to be". Teachers can apply specific strategies when dealing with difficult students.

Probably the most important aspect of a positive relationship is empathy on the part of the teacher, which results in the student feeling estimated. Empathetic relationships are especially important for difficult students. Unfortunately, empathy is a concept largely misunderstood as a form of affection or caring. On the contrary, caring and empathy are not at all the same. Adler defined empathy as "seeing with the eyes of another, hearing with the ears of another, and feeling with the heart of another". The end result of showing empathy is that the person "feels understood", which is crucial to reaching young adolescents.

Many teachers simply assume they understand the student's problems and dilemmas, and mistakenly try to communicate their understanding in ways that only distance the student. Rather than engage in a power struggle with a manipulative student, a teacher should acknowledge the skill that the student has worked so hard to develop. Give him/her credit for all of the years she has practiced the skill. This will also lead to an increase in the student's empathy from the teacher. After acknowledging the skill, reframe the skill and then redirect it. It is important that this skill be applied with sincerity. Any hint of sarcasm could lead to further alienation between the student and the teacher. Receiving admiration it from an adult often inspires immediate loyalty and respect toward a teacher. When communicated genuinely and honestly, it also increases the level of perceived empathy from an adult.

It is apparent that to follow this relationship approach, a teacher must have the capacity to suspend the flaring up of his or her own impulses and negative reactions. Adolescents are skilled at identifying the things that make teachers impatient, angry, and upset. They often share insights with each other about what annoys teachers. The ability to manage one's own impulses as they arise is one of the most demanding skills. It marks the difference between the effective and the ineffective teacher. It is also an assessment of effective relationship-based teaching. Once a professional gives in to emotions such as anger, exasperation, or displeasure, his or her ability to function becomes impaired to a degree. It is a good idea for a teacher to learn to suspend his or her own emotions as they arise - and address them later. Suspending one's own reactions is a skill that can be improved with practice.

Leaving the ego at the door of the classroom is perhaps the most valuable suggestion to offer. Students watch closely the reactions of their teachers to see if they practice what they preach. However, if a teacher tells a student to 
ignore the taunts or insults of another and then reacts angrily to being disrespected, the student will have little respect for what amounts to hypocrisy. Demanding respect is not as effective as earning it, and how the teacher comports himself or herself has much to do with how he or she is viewed and respected by students.

It is natural for teachers to get upset when a student pokes fun at a sensitive topic or issue. This is especially true when it comes to the topic of authority. Many teachers believe that they must have absolute authority in the classroom. They also believe that this authority comes automatically with their status as teachers and does not necessarily have to be earned. When students question this authority by being non-compliant or engage in disruptive behaviour, they may easily trigger an emotional reaction from the teacher. Because teachers do have authority and certain privileges afforded to them by their position, anger and frustration often lead to the abuse of power. This usually happens when the teacher does not take the opportunity to examine his/her own vulnerabilities on a regular basis. When the disruptive student repeatedly disobeys the teacher, the teacher has an ideal opportunity to apply the practice of forgetting about their ego. When a teacher is aware of his/her own vulnerabilities, they are more likely to respond strategically rather than emotionally. For example, a teacher who knows he is sensitive to students questioning his authority can anticipate that middle school students will, in fact, question his authority. Such awareness can lead to the use of empathy, as previously discussed.

Developing relationships with students who come from culturally different backgrounds can be challenging and requires specific skills from new and experienced teachers alike. The recommendations for forming relationships made earlier in this article are essential when cultural differences are present. That is, having empathy, admiring negative behaviours, and leaving one's ego at the door can go a long way toward bridging the gap between culturally or linguistically different learners and the teacher.

The challenges in this case lie in overcoming the barriers that prevent teachers from developing stronger relationships with students. These barriers exist due to a fear of different cultures, a lack of knowledge about the differences and similarities between cultures and general intolerance. To overcome these barriers, a teacher must overcome his/her fears of regarding cultural difference. This can be achieved by gaining deeper knowledge about himself or herself and the culturally different student.

It is important to help teachers become aware of how their cultural heritage may impact their classroom climates. This awareness helps prepare teachers to identify and work through any existing intolerance they may have for students who come from different ethnic, class, or religious backgrounds. It is equally important for teachers to be aware of their emotional reactions to the culturally different student. It is vital for the teacher to be aware of his or her cultural and personal biases. Then, when challenges to authority occur, the teacher who is aware of his/her "defects" is better equipped to respond in more strategic ways. Such self-examination helps teachers forget about their egos and ultimately develop empathy for their students.

Efforts to improve education must focus on the single most important component: the classroom teacher. Teachers in middle schools must be well prepared to face the challenges of working with young adolescents and critical components of teacher preparation are the knowledge and skills that will enable them to develop effective, and often unconventional, management systems in their classrooms. This effort must begin with a new paradigm in which teachers view classroom management as an ongoing exercise in building relationships.

For dealing with the most challenging of students, teachers can learn and apply strategies such as building empathy, admiring negative attitudes and behaviours, and forgetting about their own ego. It is particularly important to provide specific strategies for dealing with problems that prevent us from helping students to learn. In the area of classroom management, it is critical that teachers find ways of building relationships with all students, from the most motivated to the most difficult. To borrow the words of Rogers and Renard, when we come to understand human needs and relationship-driven teaching, "amazing things can happen".

The quality of teacher-student relationships is surprisingly stable over time. In other words, if a teacher has a conflictual relationship with a student in his earlier school years, it is likely that the teachers in the later years will also experience conflict in their relationship with the same student. This stability is more evident when the relationships are conflictual rather than when the relationships are described as close.

Several common and readily available instruments have been developed to assess teacher-student relationships. These instruments can serve as diagnostic tools to identify strengths and weakness in teaching. Some of these instruments rely on teachers' reports of relationships, others are based on teacher-student interactions in the classroom, and others rely on students' reports of their relationships with teachers.

There are also less formal ways to assess your relationships with students. We can give them anonymous questionnaires about how they feel while they are in our classroom. Through this process, it is important to realize that 
even the best teachers have difficulties with a few students from time to time. The reasons for these difficulties are numerous and getting help from other teachers or the school psychologist, may offer us an outside view of what is occurring and help us improve our relationships with the challenging students in the classroom.

When teachers use practices that demonstrate caring toward students and that foster interpersonal skills among students, students are less likely to reject one another. Also, aggressive students who have positive relationships with teachers are more likely to be accepted by peers than aggressive students who lack positive relationships with their teachers. Constructive teacher-student relationships have an important influence on the social skills of difficult students. Enhancing individual teacher-student relationships has beneficial effects for other aspects of classroom life. Such efforts improve the nature of interactions among students and promote students' engagement in school.

It is worth noting that the nature of teacher-student relationships changes depending on the age of the student involved. In other words, the behaviour that might be perceived by a younger student as caring might be perceived by adolescents as over-involved. It is also important to realize that in the early years of school, students' perception of their relationship with teachers and teachers' perception of those same relationships are quite similar. As children grow and develop, the gap between their perceptions of teachers and teachers' perception of them grows and widens. Positive, healthy relationships can help children with the developmental transitions they experience.

All of us, but particularly new teachers, struggle with deciding on an appropriate degree of openness. Students respond best to teachers who can share their beliefs and values non-judgmentally. Sharing common interests-books, music, sports, entertainment- and discussing ideas, are good foundations for a relationship. Knowing just how open to be, and how much to disclose about yourself, is a matter of personal preference and professional judgment. We do not need to become overly involved in students' lives outside of school, but they need for us to be interested enough in them to share our ideas and engage in conversation.

Occasionally, teachers share too much personal information with their students. We need to be cautious about this; as the old saying has it, "familiarity breeds contempt." When a teacher discloses too many personal details, the line between teacher and student is blurred. We must maintain our role as "teacher." We are neither students' friends nor their parents. Our influence is most clearly felt when we act within our role as teachers.

Students like and trust teachers who believe in them and believe that students can be successful both academically and socially. Communicating these beliefs is an important part of building a relationship. We often respond differently to lower-achieving students. We give them fewer opportunities to respond, shorter time periods in which to respond, and less specific feedback. Although we certainly do not do this intentionally, the fact is these behaviours do result in students feeling less valued.

It is human nature to notice misbehaviour. We see things that need attention. The trick is to not respond every time we notice! Frequent negative remarks almost always cause students to dislike school. We tend to think that critical remarks improve behaviour. Actually, research says the opposite is true. In classrooms where teachers make negative statements, students perceive them as less caring, helpful, and fair. The message that students receive from these negative statements is that they are incapable, and worthless. When this happens, students are not willing to work cooperatively with teachers. This does not mean we should allow misbehaviour to escalate. It does mean that we deal with it in more positive ways by teaching the students the appropriate behaviour and giving them support and assistance as they make the change. Teachers who see misbehaviour as a problem to be solved, rather than as a misbehaviour to punish, build far better relationships with students.

Difficult students require more energy on our part. We may need to spend time with them individually to get to know them better -- to understand their interests and what motivates them. This will not only allow us to tailor our instruction to their interests and motivation, but the time spent will also allow them to develop trust in us. When students with frequent discipline problems perceive that their teachers are trustworthy people, they show less defiant behaviour.

Getting cooperation is easier and more effective than gaining control. Let's think about changing our behaviour in order to get them to change theirs. When we give choices, we give away some of our control. Giving choices does not mean we put the student under control. We are talking about choices within limits. Giving choices avoids power struggles and teaches students to make good decisions, and to assume responsibility for the outcome. Choices are essential for the development of student self-control. When we provide the opportunity for choice, we send students powerful messages and the class climate becomes more pleasant. Stronger relationships with students result. When we let them know that they can, at least to some extent, control their own lives and that we respect their ability to do so, they begin to feel more valued and confident. The respect begins to be returned. We change our behaviour and cause students to change theirs. We give up control, but we gain influence-and influence lasts forever! 
Effective communication skills are as important in the classroom as they are in other aspects of our life. Actually, they are the foundation of good management. If we don't master the art of communication, our attempts to create a smooth management system and to build relationships with our students are limited. Communication skills are skills we use when we speak to others. Teachers use these skills to confront students about skills they need to change, to provide feedback to students and to present positive expectations to students. The language we use with our students should be a language that supports learning. Listening skills are extremely important. When teachers use listening skills effectively, students feel confident, respected, and responsible. Our job is to listen in an active way in order to help students identify the problem and work through it to a solution.

Building a classroom community goes beyond the teacher-student relationship. It encompasses the broader idea of how everyone gets along together. The way students turn out is not just a function of what they have been taught, but of how their environment has been set up. We have to pay attention to the way the classroom works and behaves-not just the way individuals work and behave. The quality of relationships that students have with their peers affects both their academic achievement and their school behaviour. Furthermore, the kinds of relationships that students form at school are the basis for those they have as adults. It is in school, where students learn the social skills, which assist both their social and emotional development. We want our classrooms to be seen as communities of learners where all students are responsible for their own learning and also the learning of others. The foundation of this community is the development of peer relationships in which students show respect for each other and have concern for the learning of their classmates.

\section{Conclusion}

Positive teacher-student relationships promote academic performance. Students who experience positive relationships with their teachers are less likely to avoid school, appeared more more cooperative, and more engaged in learning. Students display better academic performance and experience less loneliness if they have a positive relationship with their teachers. Teachers who show sensitivity to individual differences among students, include students in the decisionmaking and acknowledge students' needs produce greater motivation in their students than those who use fewer such practices. Positive relationships can also help a student develop socially. The presence of positive relationships with teachers and the experience of a positive school environment are strong indicators of academic achievement, much stronger than class size, teacher experience, or availability of instructional means. Students will be more engaged and motivated if teachers meet students' need for social connection.

\section{References}

Adelman, H. S., \& Taylor, L. (2002). School counsellors and school reform Haberman, M. (1995). STAR teachers of poverty.

Marzano, R. J. \& Marzano, J. S. (2003). The key to classroom management. Nieto, S. (1999). Affirming diversity: The socio-political context of multicultural education. Rogers, S., \& Renard, L. (1999). Relationship-driven teaching.

Schmakel, P. O. (2008). Early adolescents' perspectives on motivation and achievement. Wolk, S. (2003). Hearts and minds. 